political system and national leader. It is personal and socially conditioned. In Russia, political trust is deeply personified. In the USA the background of trust is an objective evaluation of «my personal future" (economic and social) in the context of political course of president's administration. The main part in forming this evaluation is the information from American media. That is why the crisis of political trust in USA is the crisis of national political media, and the problem of fake news is in the core of it. In these conditions, the US society can do some steps to the personification of political trust as Russian people do.

Keywords: policy, trust, political trust, paradigms, archetypes, globalization

АНДРЕЕВ Алексей Петрович - главный научный сотрудник Центра исследования проблем безопасности РАН (117335, Россия, г. Москва, ул. Гарибальди, 21б; andreev_a_p@mail.ru)

КОКУНОВА Светлана Дмитриевна - ведущий научный сотрудник Центра исследования проблем безопасности РАН (117335, Россия, г. Москва, ул. Гарибальди, 21б; svetlana.nukok@yandex.ru)

\title{
ВОПРОСЫ УКРЕПЛЕНИЯ ОБЩЕСТВЕННОЙ БЕЗОПАСНОСТИ В СВЕТЕ СОВЕРШЕНСТВОВАНИЯ РАБОТЫ ПО ПРОФИЛАКТИКЕ ПРЕСТУПНОСТИ НЕСОВЕРШЕННОЛЕТНИХ В СОВРЕМЕННЫХ УСЛОВИЯХ
}

\begin{abstract}
Аннотация. В статье исследуется вопрос об изменении структуры преступности несовершеннолетних, о роли нового поколения в социальном воспроизводстве и обеспечении общественной безопасности. Авторы анализируют современную статистическую карту преступности несовершеннолетних; обращают внимание на изменение правосознания нового поколения Z, обусловленное постоянным взаимодействием с информационными технологиями и влиянием сети Интернет, а также на смещение преступности в виртуальную среду. В статье делается вывод о необходимости новых подходов к профилактике противоправного поведения несовершеннолетних и формированию их правосознания в условиях новой формации.
\end{abstract}

Ключевые слова: общественная безопасность, постиндустриальное цифровое общество, социальное воспроизводство, преступность несовершеннолетних, правосознание

B опросы национальной безопасности страны, в т.ч. общественной безопасности, сегодня являются предметом изучения специалистов различного профиля - политиков, военных, правоохранителей, психологов, социологов, специалистов в области экономики, экологии, IT-технологий, медицины, кибернетики и др. Особую актуальность они приобретают в современную эпоху смены парадигмы общественного развития, связанной в значительной степени с информатизацией и цифровизацией всех аспектов жизнедеятельности человека.

В условиях перехода к новому технологическому укладу, ведущему к трансформации общества, существенно меняется динамика всех общественных процессов и явлений, которые приобретают новые свойства и формы и способны существенным образом повлиять на сложившуюся социальную структуру общества. В новой реальности важнейшая роль отводится новому поколению. Обладая бо́льшими информационно-технологическими образовательными возможностями, а следовательно и будущими компетенциями, молодое поко- 
ление принимает на себя колоссальную ответственность за построение постиндустриального общества.

Влияние информационных процессов в условиях глобализации общества и развития информационного пространства на социально-экономическое состояние общества, особенно на молодежь, не имеющую в достаточной мере выработанного иммунитета от информационного воздействия, в должной мере освещено в работе группы авторов под общей редакцией В.Л. Шульца и В.В. Кульбы [Шульц и др. 2015: 25-34].

Еще в 40-х гг. прошлого столетия К. Мангейм обращал внимание на то, что молодежь - это один из скрытых ресурсов, которые имеются в каждом обществе и от мобилизации которых зависит его жизнеспособность. Ученый уже тогда пришел к выводу, что динамичные общества должны опираться на молодежь. Особая ее функция состоит в том, что она - «оживляющий посредник, своего рода резерв, выступающий на передний план, когда такое оживление становится необходимым для приспособления к быстро меняющимся или качественно новым обстоятельствам» 1 .

Современное молодое поколение как основной субъект и детерминант общественного развития должно обладать способностью обеспечить функционирование интеллектуально-цифрового общества и безопасность национальногосударственной среды, во многом обусловленной процессами глобализации. Сегодня на молодое поколение ложится ответственность не просто за воспроизводство всей социальной структуры, но за воспроизводство ее в новом технологическом качестве, ориентированном на цифровую среду обитания.

Цифровая среда имеет сложную картографию и состоит из ряда развивающихся сегментов [Овчинский и др. 2014: 6]:

- Web 1 - первый простой сегмент, включающий правовые, корпоративные, общественные, персональные порталы и сайты, блоги, онлайн-СМИ;

- Web 2 - веб социальных сетей, контент которых создается, как правило, самими пользователями;

- Web 3 - веб мобильных приложений;

- «невидимый Интернет» - ресурсы, которые не обнаруживаются поисковыми системами, а также порталы и сайты, доступ к которым предполагает либо платный характер, либо наличие специального разрешения;

- «Интернет вещей» - соединение через Интернет с управляющими центрами различных объектов физического мира (электросети, водоснабжение, теплоснабжение и т.п.), а также с домашним оборудованием (холодильники, стиральные машины и т.п.);

- «бодинет» - возможность встраивать элементы, передающие информацию, в тело, предметы гардероба и нательные аксессуары;

- dark web (темный веб) - эти ресурсы широко используются преимущественно для противоправной деятельности, киберпреступности, торговли наркотиками, оружием и т.д., а также для целенаправленных акций для подрыва государственного суверенитета;

- «сети денег» включают в себя специализированные телекоммуникационные сети, связывающие крупнейшие банки, а также платежные системы типа PayPal, Яндекс.Деньги, Биткоин и т.п. [Овчинский и др. 2014: 10].

В этом мире растет и формируется поколение $Z$, имеющее с рождения опыт взаимодействия с информационно-цифровыми технологиями, что определяет их сознание и поведение. Поколение $Z$ называют также homelanders - домо-

\footnotetext{
1 Мангейм К. Социология молодежи: электронная энциклопедия (под ред. В.А. Лукова). Доступ: http://soc-mol.ru/ (проверено 03.07.2018).
} 
седы. Homelanders не просто читают, получают информацию, играют в игры и общаются в Интернете - они живут в Сети. Интернет и информационное пространство являются для них естественным продолжением личностного или группового пространства [Цымбаленко].

Свободно ориентируясь во всех названных выше сегментах информационной сети, пользователи способны влиять на тенденции легального либо противоправного использования и развития информационных ресурсов. От того, насколько устойчив правопорядок и насколько развит уровень правосознания нового «цифрового» поколения, будет зависеть безопасность национального цифрового пространства.

Преступность как явление, противоположное правопорядку, оказывает непосредственное влияние на формирование как индивидуального, так и общественного правосознания, препятствует развитию любого общества.

На формирование правосознания нового поколения продолжают оказывать влияние те же криминогенные факторы, которые оказывают влияние на современную подростковую преступность, - безнадзорность, наркомания, проявления агрессии в обществе, внутренняя и внешняя миграция, распространение экстремизма в молодежной среде, вовлечение подростков и молодежи в террористическую деятельность, деградация моральных ценностей и многие другие.

В то же время, будучи активными пользователями сети, подростки приобретают новое мироощущение и сознание, для которого не характерна ориентация на нормы права. В виртуальном пространстве существуют свои законы и правила поведения. К примеру, нарушение чужого личного пространства не считается предосудительным, издевательства в сети (троллинг) считаются нормой, злоумышленники, добывающие конфиденциальную информацию в обход систем защиты (хакеры и крэкеры), возводятся в ранг высоких профессионалов и т.д. Нормы права для них неинтересны, а правопорядок лежит в плоскости, отличной от плоскости их существования.

В современном мире эти факторы имеют глобальный характер и во многом обусловлены общемировыми тенденциями.

Многие исследователи в области психологии приходят к выводу о значительном росте интеллекта поколения $Z$. В то же время отмечается, что у молодого поколения снижаются показатели динамометрии, растет уровень наркомании, заболеваемости и смертности от наркотиков, возрастает социальное аутсайдерство, снижение способности к коллективным формам обучения и труда. Таким образом, можно предположить, что высокий уровень $I Q$ не выполняет роль социозащитного фактора, а в некоторых случаях, напротив, используется для поиска новых форм девиаций, связанных с возможностями новых технологий. Подростковая преступность плавно перетекает в интернет-пространство.

Современная статистическая карта преступности несовершеннолетних, демонстрируя противоречивые тенденции, по нашему мнению, подтверждает вышеизложенное предположение.

Начиная с 80-х гг. прошлого века уровень преступности несовершеннолетних всегда имел стойкую тенденцию роста. В доперестроечные годы в среднем через каждые 5 лет число несовершеннолетних, совершивших преступления, увеличивалось на 11-12\%. Начиная с 1991 г. в динамике преступности несовершеннолетних произошли еще более негативные изменения. Так, число несовершеннолетних, совершавших преступления в период с 1991 по 1995 г., увеличилось уже на $43 \%$ и достигло высшего уровня в 2000 г. - 190 тыс. С 2000 г. число ежегодно совершаемых несовершеннолетними преступлений стало постепенно (примерно на 5-7\% в год) снижаться и в 2006 г. составило уже 150 тыс. преступлений в год. 
Однако с 2007 г. отмечается резкий спад числа совершенных подростками преступлений при том, что этот период характеризуется начинающимися кризисными явлениями в экономике, существенным ухудшением наркоситуации и ростом преступности в целом, т.е. факторами, которые обычно называются в числе причин, повышающих уровень преступности среди несовершеннолетних.

По данным Федеральной службы государственной статистики ${ }^{1}$, уровень преступности несовершеннолетних с 2000 по 2017 г. снизился более чем на 70\%!

Таблица 1

Число преступлений, совершенных несовершеннолетними, в т.ч. в соучастии, за период с 2000 по 2017 г., тыс.

\begin{tabular}{|c|c|c|c|c|c|c|c|c|}
\hline $\mathbf{2 0 0 0}$ & $\mathbf{2 0 0 1}$ & $\mathbf{2 0 0 2}$ & $\mathbf{2 0 0 3}$ & $\mathbf{2 0 0 4}$ & $\mathbf{2 0 0 5}$ & $\mathbf{2 0 0 6}$ & $\mathbf{2 0 0 7}$ & $\mathbf{2 0 0 8}$ \\
\hline 195,4 & 185,37 & 139,68 & 145,36 & 154,14 & 154,37 & 150,26 & 139,09 & 116,09 \\
\hline $\mathbf{2 0 0 9}$ & $\mathbf{2 0 1 0}$ & $\mathbf{2 0 1 1}$ & $\mathbf{2 0 1 2}$ & $\mathbf{2 0 1 3}$ & $\mathbf{2 0 1 4}$ & $\mathbf{2 0 1 5}$ & $\mathbf{2 0 1 6}$ & $\mathbf{2 0 1 7}$ \\
\hline 94,72 & 78,54 & 71,91 & 64,27 & 67,22 & 59,54 & 61,83 & 53,73 & 48,28 \\
\hline
\end{tabular}

На диаграмме кривая преступности за этот период выглядит следующим образом (см. рис. 1).

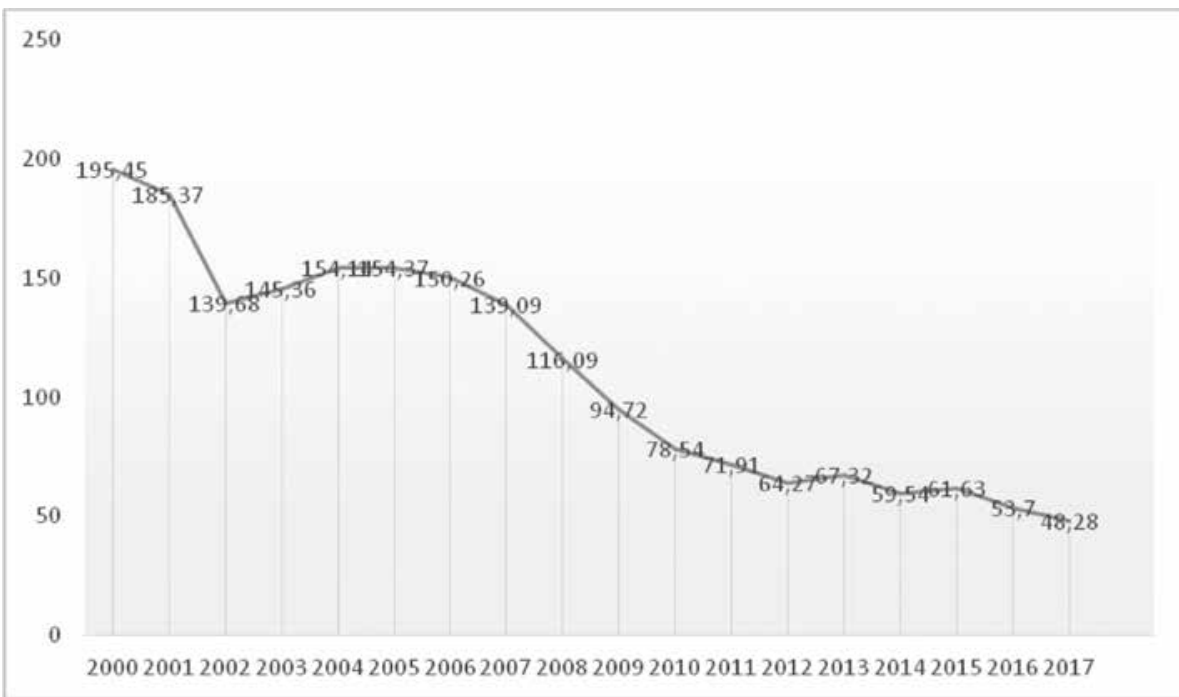

Рисунок 1. Динамика уровня преступлений, совершенных несовершеннолетними, в т.ч. в соучастии, за период с 2000 по 2017 г.

Данные Генеральной прокуратуры РФ за истекший период 2018 г. (январьмай) свидетельствуют о сохранении тенденции снижения преступности несовершеннолетних, несмотря на некоторое увеличение показателей по отдельным периодам года.

\footnotetext{
1 Официальная статистика Федеральной службы государственной статистики. Доступ: http://www. gks.ru/dbscripts/cbsd/dbinet.cgi?pl=2318013 (проверено 16.07.2018).
} 
Так, по данным Ежемесячного сборника о состоянии преступности в России за май 2018 года ${ }^{1}$, число преступлений, совершенных несовершеннолетними за период с января по май 2018 г., составило 16 991. При этом расчетный показатель за 12 месяцев текущего года предполагается ниже значения 2017 г.

К сожалению, в последнее время в научно-правой сфере изучению причин резкого снижения уровня преступности несовершеннолетних не уделено должного внимания. Не выявлены и не проанализированы факторы, повлиявшие на резкое снижение показателей уровня преступности несовершеннолетних, не исследована обоснованность приведенных данных, их достоверность и соотносимость.

Основными причинами столь небывалого снижения уровня преступности несовершеннолетних полагаются:

1) демографическая ситуация: снижение с 2000 г. почти вдвое числа несовершеннолетних, достигших возраста уголовной ответственности (14-18 лет), за счет снижения рождаемости и негативных показателей смертности населения России;

2) возникшее численное преимущество сотрудников субъектов профилактики над сократившимся числом несовершеннолетних, в основном за счет числа сотрудников оперативных подразделений и подразделений по профилактике и межведомственному взаимодействию органов по контролю за оборотом наркотиков (до 2016 г.);

3) усиленная система профилактики, пропаганда здорового образа жизни, принятие соответствующих целевых программ;

4) сокрытие правонарушений несовершеннолетних как в быту, так и в образовательных учреждениях.

Однако, учитывая психологические особенности подростковой среды и особенности современных тенденций развития общества и индивида, удовлетворяться только этими объяснениями было бы несправедливо и в какой-то мере опасно.

Представляется, что немалая доля из тех 70\%, на которые произошло снижение уровня преступности несовершеннолетних за последние 15 лет, приходится на трансформацию уличной преступности в сетевую.

Учитывая способности подростков в овладении компьютерными технологиями, даже такие преступления, как мошенничество в сети Интернет (картинг, фишинг, попрошайничество), создание и распространение вредоносных программ и вирусов, неправомерный доступ к компьютерным сетям (хакерство), создание организованных преступных групп, торговля оружием, терроризм и др. становятся доступными и для лиц, не достигших возраста 18 лет. А такие явления, как интернет-торговля наркотиками, сетевая педофилия, кибермоббинг (травля и доведение до самоубийства через Интернет), наиболее популярны как раз в подростковой среде.

Так, например, впервые широко о проблеме суицидальной пропаганды в Интернете заговорили в конце 2014 г., когда в соцсетях резко активизировались сообщества суицидальной направленности. Вступить в них мог любой желающий. Число подписчиков в некоторых группах достигало 10-12 тыс. чел. В этих группах размещались видеозаписи со сценами самоубийств, психоделический контент, подробно описывались способы совершения самоубийств, обсуждались громкие истории подростковых самоубийств с героизацией погибших

\footnotetext{
${ }^{1}$ Ежемесячный сборник о состоянии преступности в России за май 2018 г. - Генеральная прокуратура РФ. Портал правовой статистики. С. 9. Доступ: http://crimestat.ru/analytics (проверено 16.07.2018).
} 
детей, самоубийство преподносилось как способ освободиться от всех проблем, стать известным и популярным ${ }^{1}$.

Преступления, совершаемые в киберпространстве, совершаются в условиях изоляции и самоизоляции и часто по своей сути имеют латентную форму. Доказывание их нередко затруднено как с уголовно-правовой, так и с процессуальной точки зрения. Кроме того, возросшая толерантность общества к антиобщественным и аморальным проявлениям, особенно в сети Интернет, не способствует выявлению таких преступлений. Ситуация осложняется глобальным социальным аутсайдерством, которому подвержены различные социальные и возрастные группы, в первую очередь старшие школьники.

Эти обстоятельства свидетельствуют об усложнении структуры преступности несовершеннолетних.

Однако обнадеживает тот факт, что даже на фоне резкого снижения показателей преступности лиц, не достигших возраста 18 лет, государственная политика все же не снизила интенсивность регулирования деятельности по профилактике преступности среди несовершеннолетних.

22 марта 2017 г. правительство РФ утвердило Концепцию развития системы профилактики безнадзорности и правонарушений несовершеннолетних на период до 2020 года ${ }^{2}$.

Как указывается в Концепции, участниками преступлений в 2016 г. стали 48600 подростков. Несовершеннолетними и при их соучастии совершено 53700 преступлений. В конце 2016 г. на учете в подразделениях по делам несовершеннолетних органов внутренних дел состояли 142800 несовершеннолетних. В указанном периоде снизилось число преступлений, совершаемых подростками в состоянии алкогольного опьянения, однако выросло число преступлений, совершаемых в состоянии наркотического опьянения. Как отмечается в документе, не теряет актуальности проблема повторной преступности несовершеннолетних, состоящих на учете в уголовно-исполнительных инспекциях. В 2016 г. 15,5\% несовершеннолетних, состоявших на учете в уголовно-исполнительных инспекциях, ранее привлекались к уголовной ответственности, более $27,7 \%$ осуждены за совершение тяжких и особо тяжких преступлений.

Следует обратить внимание и на повышение удельного веса групповых, организованных, заранее подготавливаемых, изощренных и технически оснащенных преступлений, совершаемых лицами, не достигшими возраста 18 лет. Доля групповых преступлений в преступности несовершеннолетних обычно в 2-5 раз выше, чем аналогичный показатель преступности взрослых. Ежегодно более половины всех несовершеннолетних совершают преступления в составе групп. Зачастую несовершеннолетние объединяются в целые преступные формирования, где имеется, как правило, взрослый консультант. Многие из активных членов преступных молодежных группировок становятся в последующем лидерами криминальных сообществ. На протяжении ряда лет, как отмечено в Концепции, сохраняется высокая криминальная активность подростков младших возрастных групп.

Таким образом, можно обоснованно прийти к выводу, что на фоне резкого снижения общего уровня преступности несовершеннолетних происходят следующие явления:

\footnotetext{
1 Доведение до самоубийства через интернет-ресурсы. С. 4. Доступ: https://megalektsii.ru/s36803t7. html (проверено 16.07.2018).

2 Распоряжение Правительства РФ от 22.03.2017 № 520-р «Об утверждении Концепции развития системы профилактики безнадзорности и правонарушений несовершеннолетних на период до 2020 года». - Собрание законодательства РФ. 2017. № 14. Ст. 2088.
} 
- повышается число тяжких и особо тяжких преступлений, совершенных несовершеннолетними или с их участием;

- повышается число преступлений, совершенных несовершеннолетними или с их участием, в составе преступных групп, в т.ч. с применением оружия;

- растет число преступлений, совершаемых в состоянии наркотического опьянения;

- повышается уровень вовлеченности в противоправную деятельность несовершеннолетних, не достигших возраста уголовной ответственности;

- существенно меняется структура преступности несовершеннолетних в сторону отягчения;

- растет число противоправных и антиобщественных проявлений в отношении самих несовершеннолетних.

Все эти факторы повышают концентрацию и общественную опасность преступности несовершеннолетних, усложняют криминогенную ситуацию, являющуюся элементом воспроизводства преступности и ее непременным спутником.

Наряду с этим растет число преступлений, совершаемых несовершеннолетними с использованием компьютерных технологий. Меняется структура преступности несовершеннолетних: она делится на преступность материальную и преступность виртуальную. Уже становится очевидным, что сам по себе более высокий уровень интеллекта нового поколения, его информационно-технологическая образованность и потенциальные компетенции не обеспечивают снижение криминогенности будущего взрослого социума.

Представляется, что это обстоятельство должно выступать побудительным мотивом для модернизации подходов к профилактике противоправного поведения несовершеннолетних и формированию их правосознания в условиях новой формации.

\section{Список литературы}

Овчинский В.С. и др. 2014. Россия и вызовы цифровой среды: рабочая тетрадь (гл. ред. И.С. Иванов). РСМД. М.: Спецкнига. 40 с.

Цымбаленко С.Б. Российские подростки в информационно-коммуникативном обществе. Доступ: http://mim.org.ru/phocadownload/cimbalenko.pdf (проверено 16.07.2018).

Шульц В.Л., Кульба В.В., Шелков А.Б., Чернов И.В. 2015. Сиенарный анализ и управление геополитическим информационным пространством. Центр исследования проблем безопасности РАН. М.: Наука. 542 с.

ANDREEV Aleksei Petrovich, Chief Researcher of the Center for Security Studies, RAS (216 Garibaldi St, Moscow, Russia, 117335; andreev_a_p@mail.ru)

KOKUNOVA Svetlana Dmitrievna, Leading Researcher of the Center for Security Studies, RAS (216 Garibaldi St, Moscow, Russia, 117335; svetlana.nukok@yandex.ru

\section{ISSUES OF STRENGTHENING PUBLIC SECURITY IN THE LIGHT OF IMPROVING THE PREVENTION OF JUVENILE CRIME IN MODERN CONDITIONS}

Abstract. The article examines the question of changing the structure of juvenile delinquency, the role of the new generation in social reproduction and public safety. The authors analyze modern statistical map of juvenile delinquency and pay attention 
to the change of the legal consciousness of the new generation Z due to the constant interaction with information technology and the impact of the Internet, as well as the shift of crime in the virtual environment. The authors conclude that new approaches to the prevention of illegal behavior of minors and the formation of their legal consciousness in the new formation is needed.

Keywords: public safety, post-industrial digital society, social reproduction, juvenile delinquency, legal awareness

АБДУЛЬЗянОВ Артур Рашидович - кандидат социологических наук, ведущий научный сотрудник Центра семьи и демографии Академии наук Республики Татарстан, генеральный директор Федерации автошкол Республики Татарстан (420111, Россия, Республика Татарстан, г. Казань, ул. Лево-Булачная, 35a;gailj_07@bk.ru)

\section{БЕЗОПАСНОСТЬ ДОРОЖНОГО ДВИЖЕНИЯ В СИСТЕМЕ ГОСУДАРСТВЕННОЙ ПОЛИТИКИ CTPAHЫ}

Аннотация. В статье рассматривается проблема обеспечения безопасности дорожного движения как приоритетная задача государственной политики страны. Эффективная работа в данной сфере способствует снижению депопуляции населения, а также экономических затрат, связанных с последствиями дорожно-транспортных происшествий, что способствует социально-экономическому развитию страны. Ключевые слова: безопасность, безопасность дорожного движения, государственная политика, Госавтоинспекция

Сегодня одной из острейших социальных проблем в мире является проблема безопасности дорожного движения, поскольку на автомобильных дорогах всех стран наблюдается высокий уровень аварийности, что, в свою очередь, приводит к постоянному росту числа погибших и пострадавших в дорожнотранспортных происшествиях.

Дорожно-транспортные происшествия носят социальный и экономический характер. По сведениям Всемирной организации здравоохранения, каждый год на дорогах всего мира гибнут свыше 1,2 млн чел., в т.ч. больше 163 тыс. детей, не достигших возраста 15 лет. По прогнозам данной организации, проблема дорожно-транспортного травматизма может стать к 2020 г. еще более серьезной и занять 3-е место среди первостепенных причин смерти и телесных повреждений у людей ${ }^{1}$. Суммарная убыль населения от дорожно-транспортных происшествий составляет более 2,1\% [Блинкин 2012: 18]. Во всем мире на сегодняшний день дорожные происшествия на дорогах (аварии) являются основной причиной гибели и инвалидности людей в возрастном диапазоне от 3 до 35 лет. Дорожно-транспортные происшествия в развитых странах обусловливают ежегодные потери в размере от 1 до 3\% внутреннего валового продукта, а в развивающихся - издержки еще больше. Для мировой экономики уже сейчас ущерб от дорожно-транспортного происшествия носит и экономический характер: для экономики всего мира он насчитывает примерно 600 млрд евро в год. В свою очередь, в экономически развитых странах ситуация с безопасностью дорожного движения за последние 30 лет стабилизировалась и даже улучшилась, но

\footnotetext{
1 Доклад о состоянии безопасности дорожного движения в мире: краткий обзор ВОЗ. Доступ: http:// apps.who.int/iris/bitstream/handle/10665/70041/WHO_NMH_VIP_09.01_rus.pdf;jsessionid=D71451A22B 351F65A284BC5DAF7BE68E?sequence=5 (проверено 18.08.2018).
} 